\title{
Effect of Sevoflurane Preconditioning on Inflammatory Cytokines and Oxygen Radicals During Single Lung Ventilation in Patients with Lung Cancer
} Hao Zhang, Yilu Zhou, Yinglin Wang and Qingxiu Wang*

Department of Anaesthesiology, Shanghai East Hospital, Tongji University School of Medicine, China

\begin{abstract}
Objective: To observe the effect of sevoflurane preconditioning on inflammatory cytokines and oxygen radicals during single lung ventilation (SLV) in patients with lung cancer and to discuss the mechanism of sevoflurane induced lung protection.

Methods: Thirty patients, ASA I or II, with non-small-cell lung cancer underwent pulmonary surgeries were randomized into two groups: sevoflurane preconditioning group (group $S, n=15$ ) and control group (group $C, n=15)$. After general anaesthesia induction. A double-lumen tube was placed and the position was checked by a fibre optic bronchoscope. During the mechanical ventilation, patients in group $\mathrm{S}$, received sevoflurane at 1.0 minimum alveolar concentration (MAC) for $30 \mathrm{~min}$ as a preconditioning and then replaced by oxygen for a complete rapid gas exchange to reduce the sevoflurane inhalation concentration to 0 before SLV. While in group C, only intravenous anaesthetic agents, fentanyl and propofol, were administrated before SLV. Blood concentrations of TNF- $\alpha$, IL-6, IL-8, SOD and MDA were measured at Post-induction of anaesthesia (T1), $30 \mathrm{~min}$ after SLV in the lateral position (T2), 60 min after SLV in the lateral position (T3), and at the end of the operation (T4).
\end{abstract}

Results: When compared with TI, the concentrations of TNF- $\alpha$, IL- 6 and MDA in both groups and the IL-8 in group $S$ were significantly increased at T2-T4 $(P<0.05)$, while the expression of SOD in two groups were decreased significantly $(P<0.05)$. The concentrations of TNF- $\alpha, I L-6, I L-8$ and MDA in group $S$ were decreased significantly at T2-T4 $(P<0.05$ or $P<0.01)$ when compared with those in group $C$. The activity of SOD in group $S$ was significantly increased at T3 and T4 $(P<0.05)$.

Conclusion: Sevoflurane preconditioning may moderate the release of inflammatory cytokines to inhibit the inflammatory reaction and may reduce the lipid peroxidation by inhibiting the generation of oxygen free radical. It may protect the lung from the injury during SLV.

Keywords: Sevoflurane preconditioning; Cytokine; Oxygen free radical; Single lung ventilation

\section{Introduction}

Single lung ventilation (SLV) is a common way of ventilation, with its application in lung cancer surgery, lung injury caused by SLV has raised widely attention. Sevoflurane is a type of inhalation anaesthetics medicine, it is features for rapid awakening and easy to control, has been widely used in recent years. Studies have shown that sevoflurane pre-treatment could have effect of lung protective, think that inhaled sevoflurane pre-treatment can reduce the lungs injury, protect lung function in patients with lung cancer during SLV. Also, Oxygen free radicals and inflammatory cytokines plays an important role in the lung injury. This study aim to observe the sevoflurane preconditioning in patients with lung cancer underwent SLV and the influence of inflammatory cytokines and oxygen free radicals, investigate the lung protection mechanism of sevoflurane.

\section{Materials and Methods}

\section{General information}

We enrolled 30 patients with non-small cell lung cancer from March 2015 to March 2016. male 15 cases, 15 cases were female, aged 40 to 65 , weight $50 \mathrm{~kg}$ to $75 \mathrm{~kg}$, ASA I or II level. Exclusion criteria were as follows: cervical spine disease that restricted head extension; oropharyngeal disease; presence of loose or vulnerable teeth. Preoperative patients accepted chemotherapy two period, all patients were given medicine to prevent nausea and vomiting. Patients were randomly allocated by an independent anaesthesiologist (Lihua Wang) into either sevoflurane preconditioning group (group S) or control group (group C).

\section{Anaesthesia methods}

Each patient was laid on the operating table, non-invasive blood pressure, three-lead ECG, and oxygen saturation were monitored. Anaesthesia was induced with: intravenous midazolam $0.04 \mathrm{mg} / \mathrm{kg}$, fentanyl $1.4 \mu \mathrm{g} / \mathrm{kg}$, TCI propofol $3.5 \mu \mathrm{g} / \mathrm{ml}$ and atracurium $0.2 \mathrm{mg} / \mathrm{kg}$. Patients were intubated with a double-lumen tube with the help of fibre optic bronchoscope. Underwent mechanical ventilation, set $\mathrm{V}_{\mathrm{T}} 6 \mathrm{ml} /$ $\mathrm{kg} \sim 8 \mathrm{ml} / \mathrm{kg}$, RR 10/min $\sim 14 / \mathrm{min}, \mathrm{P}_{\mathrm{ET}} \mathrm{CO}_{2} 35 \mathrm{mmHg}$ to $45 \mathrm{mmHg}$. In group $S$, after successful intubation, inhalation sevoflurane for 30 min before SLV, after the completion of sevoflurane pre-treatment, maintain at 1.0 minimum alveolar concentration (MAC) effectively, stop using sevoflurane pre-treatment. Then using $100 \%$ concentration oxygen exchange sevoflurane, before make SLV, sevoflurane inhalation

*Corresponding author: Wang Q, Department of Anaesthesiology, Shanghai East Hospital, Tongji University School of Medicine, 150 Jimo Road, Shanghai 200120, China, Tel: + 862161569776; E-mail: qxw1123@126.com

Received October 05, 2016; Accepted November 25, 2016; Published November 28 2016

Citation: Zhang H, Zhou Y, Wang Y, Wang Q (2016) Effect of Sevoflurane Preconditioning on Inflammatory Cytokines and Oxygen Radicals During Single Lung Ventilation in Patients with Lung Cancer. J Cancer Sci Ther 8: 274-276. doi: 10.4172/1948-5956.1000426

Copyright: $\odot 2016$ Zhang $\mathrm{H}$, et al. This is an open-access article distributed under the terms of the Creative Commons Attribution License, which permits unrestricted use, distribution, and reproduction in any medium, provided the original author and source are credited. 
concentration to 0 . In group C Propofol $3.5 \mu \mathrm{g} / \mathrm{ml}$ and fentanyl $4 \mu \mathrm{g} /$ $\mathrm{kg}$ intravenous infusion maintenance of anaesthesia to SLV start. Both groups maintain the anaesthesia with TCI propofol $3.5 \mu \mathrm{g} / \mathrm{ml}$, fentany $1.4 \mu \mathrm{g} / \mathrm{kg}$ and atracurium $0.2 \mathrm{mg} / \mathrm{kg}$ to maintain muscle relaxant. Maintain the BIS between 40 60, if necessary, to give vasoactive drugs.

\section{Observing indexes}

At time of Post-induction of anaesthesia (T1), SLV after $30 \mathrm{~min}$ in the lateral position (T2), SLV after $60 \mathrm{~min}$ in the lateral position (T3), and at the end of the operation (T4), From the right internal jugular vein to collect the static Vein blood, serum after centrifugation, cryopreservation unified detection. Determination of blood tumour necrosis factor (TNF- $\alpha$ ), IL - 6, IL-8 and malondialdehyde (MDA) concentration and superoxide dismutase (SOD) activity, operating in accordance with the kit instructions. Records of patients who infusion, blood loss, the first second forced expiratory volume $\left(\mathrm{FEV}_{1}\right)$, operation time and SLV time. Using SPSS 18.0 statistical analysis software for data processing, using $t$ test, group is adopted from repetitive measure analysis of variance.

\section{Results}

There was no statistically significant difference compared two groups of patients with general data (Table 1). Compared with the T1, at time T2 T4, two groups of concentration of TNF- $\alpha$ and concentration of IL-6 significantly increased. At time T3 and T4, two groups of concentration of IL-8 concentration increased significantly $(\mathrm{P}<0.05)$. Compared with group $\mathrm{C}$, at timeT2 T4, in group $\mathrm{S}$, concentration of TNF- $\alpha$, IL- 6 and IL-8 significantly decreased $(\mathrm{P}<0.05$ or $\mathrm{P}<0.01)$ (Table 2$)$.

Compared with the time T1, at time T2 T4, two groups of SOD activity decreased obviously $(\mathrm{P}<0.05), \mathrm{MDA}$ concentration increased significantly $(\mathrm{P}<0.05)$. Compared with group $\mathrm{C}$, At timeT3, T4. group $S$ SOD activity significantly increased $(\mathrm{P}<0.05)$, MDA concentration significantly decreased $(\mathrm{P}<0.05$ or $\mathrm{P}<0.01)$ (Table 3$)$. Two groups of patients with surgical time, SLV, FEV1, and transfusion volume and the bleeding comparative differences had no statistical significance.

\section{Discussion}

TNF- $\alpha$ as early inflammatory factors may induce other inflammatory

\begin{tabular}{|c|c|c|c|c|}
\hline Group & Number & Male/Female & Age (Year) & Weight (kg) \\
\hline S & 15 & $6 / 9$ & $55.2 \pm 10.4$ & $70.7 \pm 10.8$ \\
\hline C & 15 & $9 / 6$ & $56.7 \pm 12.6$ & $67.6 \pm 9.4$ \\
\hline
\end{tabular}

Table 1: General conditions. mediators, including the release of IL-6, IL-8, start the inflammatory cascade reaction, induction of neutrophil degranulation and the endothelial cell adhesion, IL- 6 is strongest in former inflammatory cytokines, inflammatory mediators related to the strict degree of tissue damage and duration, [1] reflect the operation stress caused by the severity of the inflammatory response, IL- 8 is acknowledged as the inflammatory reaction in the specific cytokines lead to lung tissue damage, the white blood cells have strong chemotaxis. In this study, maintain $\mathrm{P}_{\mathrm{ET}} \mathrm{CO}_{2}$ anaesthesia in the normal range, by the BIS monitoring anaesthesia depth at the same level. per the results of this study, two groups of patients with TNF- $\alpha$, IL-6, concentration of IL-8 with SLV increased with the extension of time, the instructions SLV make TNF- $\alpha$, IL-6, IL- 8 levels and cause lung damage. Studies have reported that sevoflurane by lowering the serum concentration of TNF- $\alpha$ and IL-8. SLV lung injury caused by protection, inhibiting the release of TNF- $\alpha$ sevoflurane pre-treatment, inhibit sexual response, pneumonia after $\mathrm{CPB}$ in early lung injury after $\mathrm{CPB}$ not only has certain protective effect [2], but also to IL-8 and inflammatory factor has inhibitory effect., according to the results of this study compared with group C, group S TNF- $\alpha$ after SLV, IL- 6 and IL-8 concentration significantly decreased, show that sevoflurane preconditioning can inhibit the expression of inflammatory cytokines or release, so as to reduce its damage of endothelial cells and the surrounding tissue, reducing the level of inflammatory response in lung injury after SLV has certain protective effect, but its mechanism still need further study.

SOD is one of the mediated endogenous antioxidant mechanism, is a major enzyme the body of free radicals [3], SOD activity and indirectly reflect the organization's ability to remove free radicals, MDA is a decomposition product of lipid peroxidation levels of MDA in the blood change reflects the change of oxygen free radicals in the organization, by measuring the MDA and SOD can reflect the occurrence of oxygen free radicals. In this study, $30 \mathrm{~min}$ after SLV is two groups of SOD activity gradually reduced, MDA concentration increased significantly, explain SLV is caused by oxygen free radicals. Compared with group C, $60 \mathrm{~min}$ after SLV, never put off till tomorrow what you can obviously increase the SOD activity, and MDA concentration is reduced, that sevoflurane pre-treatment can reduce the generation of oxygen free radicals. And 30 min after SLV [4], group S MDA concentration higher than that of group $\mathrm{C}$, the role of sevoflurane metabolism in the body could be produced in the process of oxidation to alkyl peroxide further to produce oxygen free radical, antioxidant mechanism of jump-starting the body, inhibition of oxygen free radicals generated in the end [5].

\begin{tabular}{|c|c|c|c|c|c|c|}
\hline Index & Group & Number & $\mathrm{T1}$ & T2 & T3 & T4 \\
\hline \multirow{2}{*}{ TNF- $\alpha$} & $S$ & 15 & $4.9 \pm 1.4$ & $10.6 \pm 1.6^{\mathrm{ac}}$ & $22.2 \pm 4.0^{\mathrm{ac}}$ & $31.6 \pm 5.7^{\mathrm{ac}}$ \\
\hline & $\mathrm{C}$ & 15 & $5.0 \pm 1.3$ & $16.5 \pm 3.1^{\mathrm{a}}$ & $40.6 \pm 7.8^{\mathrm{a}}$ & $45.8 \pm 8.3^{a}$ \\
\hline \multirow{2}{*}{ IL-6 } & S & 15 & $11.0 \pm 1.5$ & $16.6 \pm 4.1^{\mathrm{ac}}$ & $31.3 \pm 8.6^{\mathrm{ab}}$ & $40.8 \pm 6.6^{\mathrm{ac}}$ \\
\hline & C & 15 & $10.6 \pm 1.3$ & $26.5 \pm 9.8^{a}$ & $38.5 \pm 10.4^{a}$ & $51.0 \pm 6.1^{a}$ \\
\hline \multirow{2}{*}{ IL-8 } & $\mathrm{S}$ & 15 & $9.1 \pm 1.1$ & $10.3 \pm 2.4^{b}$ & $13.8 \pm 2.6^{\mathrm{ab}}$ & $21.3 \pm 4.7^{\mathrm{ab}}$ \\
\hline & $\mathrm{C}$ & 15 & $8.9 \pm 1.0$ & $12.1 \pm 1.9^{a}$ & $14.3 \pm 3.4^{a}$ & $26.6 \pm 3.2^{a}$ \\
\hline
\end{tabular}

Compared with the T1, aP $<0.05$; Compared with Group C, ${ }^{b} P<0.05,{ }^{c} P<0.01$

Table 2: The comparison of two groups of patients with different time point TNF- $\alpha, \quad$ IL-6, IL-8 concentration.

\begin{tabular}{|c|c|c|c|c|c|c|}
\hline Index & Group & Number & T1 & T2 & T3 & T4 \\
\hline \multirow{2}{*}{ SOD } & $S$ & 15 & $100.2 \pm 8.7$ & $94.9 \pm 9.8^{\mathrm{a}}$ & $90.1 \pm 10.6^{\mathrm{ac}}$ & $84.1 \pm 10.7^{\mathrm{ab}}$ \\
\hline & C & 15 & $102.9 \pm 11.5$ & $92.9 \pm 10.2^{\mathrm{a}}$ & $86.2 \pm 9.4^{a}$ & $78.5 \pm 11.0^{\mathrm{a}}$ \\
\hline \multirow{2}{*}{ MDA } & $S$ & 15 & $4.3 \pm 0.8$ & $5.2 \pm 0.8^{a}$ & $5.8 \pm 1.2^{\mathrm{ab}}$ & $6.7 \pm 1.0^{\mathrm{ab}}$ \\
\hline & $\mathrm{C}$ & 15 & $4.2 \pm 0.7$ & $5.0 \pm 0.9^{a}$ & $6.4 \pm 0.8^{a}$ & $8.2 \pm 1.2^{\mathrm{a}}$ \\
\hline
\end{tabular}

Compared with the T1, ${ }^{\mathrm{P}} \mathrm{P}<0.05$; Compared with Group C, ${ }^{\mathrm{b}} \mathrm{P}<0.05,{ }^{\mathrm{c}} \mathrm{P}<0.01$

Table 3: Two groups of patients with the comparison of different time points of SOD activity and MDA concentration. 
Citation: Zhang H, Zhou Y, Wang Y, Wang Q (2016) Effect of Sevoflurane Preconditioning on Inflammatory Cytokines and Oxygen Radicals During Single Lung Ventilation in Patients with Lung Cancer. J Cancer Sci Ther 8: 274-276. doi: 10.4172/1948-5956.1000426

To sum up, sevoflurane pre-treatment process by inhibiting the expression of inflammatory cytokines or release, reduce the production of oxygen free radicals, eventually produce protective effect in the process of SLV lung injury. Sevoflurane inhalation in advance for the use of optimal concentration and its protective mechanism remains to be step in the research.

\section{References}

1. Zhao S, Wu J, Guo Q, Zhang Z, Ye Z (2010) Effect of different concentrations of sevoflurane pretreatment on acute lung injury induced by endotoxin in rats. Journal of Central South University. Medical Sciences 35: 921-927.
2. Suter D, Spahn DR, Blumenthal S, Livia R, Christa B, et al. (2007) The immunomodulatory effect of sevoflurane in endotoxin-injured alveolar epitheliail cells. Anesth Analg 104: 638-645.

3. $\mathrm{NgA}$, Swanevelder J (2011) Hypoxaemia associated with one-lung anaesthesia: new discoveries in ventilation and perfusion. $\mathrm{Br} \mathrm{J}$ Anaesth 106: 761-763.

4. Takaono M, Yogosawa T, Okawa-Takatsuji M, Aotsuka S (2002) Effects intravenous anesthetics on interleukin (IL-6) and IL-I0 production by lipopolysaccharide-stimulated mononuelear cells from healthy volunteers. Acta Anaesthesiol Scand 46: 176-179.

5. Deforge LE, Fantone JC, Kenney JS, Remick DG (1992) Oxygen radical scavengers selectively inhibit interleukin 8 production in human whole blood J Clin Invest 90: 2123-2129. 